\title{
Continuous-flow left ventricular assist device: Current knowledge, complications, and future directions
}

\author{
Javier Castrodeza ${ }^{1,2} \oplus$, Carlos Ortiz-Bautista ${ }^{1,2}$, Francisco Fernández-Avilés ${ }^{1,2,3}$ \\ ${ }^{1}$ Cardiology Department, Hospital Universitario Gregorio Marañón, Madrid, Spain \\ ${ }^{2}$ CIBER de Enfermedades Cardiovasculares (CIBER - CV), Spain \\ ${ }^{3}$ Universidad Complutense, Madrid, Spain
}

\begin{abstract}
Long-term continuous-flow left ventricular assist devices have become a real alternative to heart transplantation in patients with advanced heart failure, achieving a promising 2-year event-free survival rate with new-generation devices. Currently, this technology has spread throughout the world, and any cardiologist or cardiac surgeon should be familiar with its fundamentals and its possible complications as well as the advances made in recent years. The aim of this review is to describe current knowledge, management of complications, and future directions of this novel heart-failure therapy. (Cardiol J 2022; 29, 2: 293-304)
\end{abstract}

Key words: continuous flow, mechanical circulatory support, left ventricular assist device

\section{Introduction}

Several advances have been made in the field of the treatment of heart failure (HF), and they have been published recently in the AHA/ACC Expert Consensus Decision Pathway for Optimization of Heart Failure Treatment and in the European Guidelines for the diagnosis and treatment of acute and chronic HF [1, 2]. Nevertheless, in advanced HF patients, the use of cardiac resynchronization therapy, implantable defibrillators, and left ventricular assist devices (LVAD) has changed the prognosis in HF dramatically [1-4]. Since 2001, when the REMATCH study was released [4], which used the LVAD (HeartMate I, HeartMate vented electric device, Thoratec, Pleasanton, California, USA), several technical improvements have been implemented. In this trial, survival at 1 year was $52 \%$ in the device group vs. $25 \%$ in the medical-therapy group; however, several adverse events were observed: a $28 \%$ rate of infection at
3 months, a $42 \%$ rate of bleeding at 6 months, and a $35 \%$ rate of pump failure at 24 months, leading to a $23 \%$ probability of survival at 2 years in the device group. This scenario has changed drastically with the new generation of magnetically levitated centrifugal pumps (Heart Mate 3, St. Jude Medical). In the MOMENTUM-3 trial [5], pump thrombosis resulting in reoperation was only $1 \%$, compared with $11 \%$ with the HeartMate II axial-flow device (HeartMate II, HeartMate vented electric device, Thoratec, Pleasanton, California, USA).

The prognosis in advanced HF is extremely poor, with a 1-year mortality in ambulatory class III-IV patients higher than 25\%, and exceeding $50 \%$ in class IV patients $[6,7]$. Heart transplantation is an excellent treatment option for many patients, but suitable donor availability is limited. Improvements in technology have made LVAD an option for patients with advanced HF. Its development over the last decade has led to a widespread use of continuous flow left ventricular (LV) pumps,

Address for correspondence: Javier Castrodeza, MD, Cardiology Department, Hospital General Universitario Gregorio Marañón, Madrid, Doctor Esquerdo, 46, 28007 Madrid, Spain, tel: (+34) 915868290, e-mail: jcastrodeza5@gmail.com

Received: $17.10 .2021 \quad$ Accepted: $3.12 .2021 \quad$ Early publication date: 28.12.2021

This article is available in open access under Creative Common Attribution-Non-Commercial-No Derivatives 4.0 International (CC BY-NC-ND 4.0) license, allowing to download articles and share them with others as long as they credit the authors and the publisher, but without permission to change them in any way or use them commercially. 


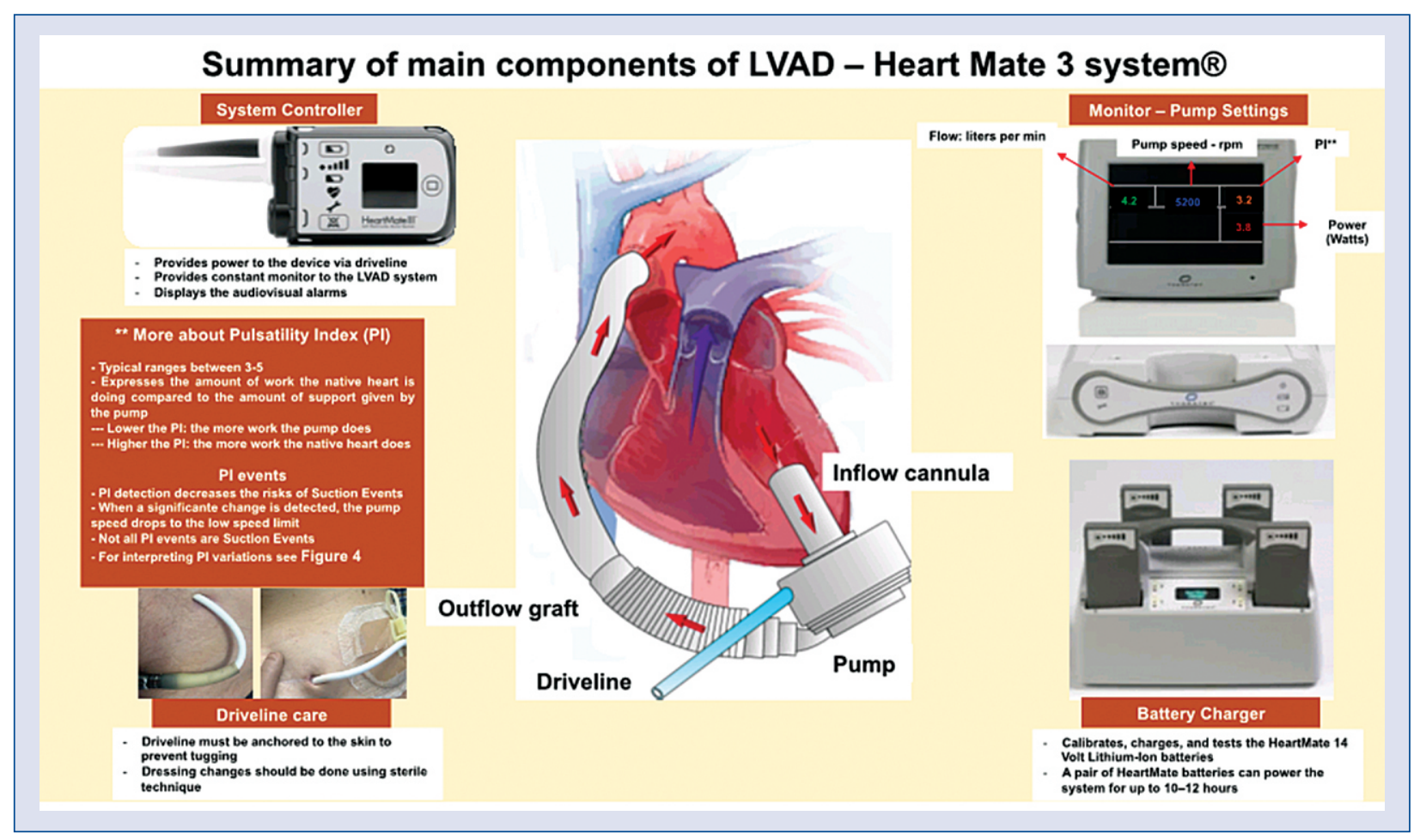

Central illustration. Summary of main components of left ventricular assist devices — HeartMate 3 system ${ }^{\circledR}$.

either as a destination therapy or as bridge to transplantation [8].

The aim of this review is to describe the current knowledge, management of complications, and future directions of this hopeful therapy. Main components of LVAD HeartMate 3 system are represented in the Central illustration.

\section{Current knowledge: Physiology, unloading the left ventricle}

In 2015 a new generation of magnetically levitated centrifugal pumps (HeartMate 3, St. Jude Medical) successfully completed a CE mark study and became available in Europe [9-12]. The technology is based on fully electromagnetic levitation pumps, reducing the friction between the rotor components, resulting in better hemocompatibility and reducing the rate of device thrombosis. The pump unloads the heart via a system that consists of an inflow cannula placed surgically into the LV apex, and an outflow graft anastomosed normally to the ascending aorta [13]. The pressure difference between the inflow and the outflow port is usually called the "delta pressure", and it reflects the differential pressure between the ventricular cavity and the aorta. Continuous flow centrifugal pumps present a curve of flattened operation, which means that they can work over a very wide range of flows with a small change in the "delta pressure". In the same way, small changes in "delta pressure" produce larger changes in the flow across the pump (Fig. 1).

This curve flow "delta pressure" explains why centrifugal pumps can show some pulsatility in response to dynamic ventricular pressures at each part of the cardiac cycle (Fig. 2) [14, 15]. In summary, continuous-flow centrifugal pumps lead to a greater degree of flow variability across the cardiac cycle (less flow in diastole and higher flow in systole) according to changes in "delta pressure". In theory, this results in centrifugal pumps having a greater aortic pulse pressure and much less propensity to create LV collapse or a suction event.

The rotor of the pump is fully supported by magnetic levitation, as mentioned, avoiding any mechanical or fluid bearings and essentially eliminating mechanical wear, leading to a better hemocompatibility. The inflow cannula is placed into the LV and consists of a cylindrical conduit rigidly affixed to the pump. The outflow graft is made of a sealed woven polyester graft and is attached to the pump by a "no-kink" sealing device. Its distal end is designed to be cut at a desired length and sutured to the ascending aorta by the cardiac surgeon with an end-to-aside anastomosis. A reinforced tube serves to prevent kinking of the outflow graft [16-18]. If necessary, the outflow 


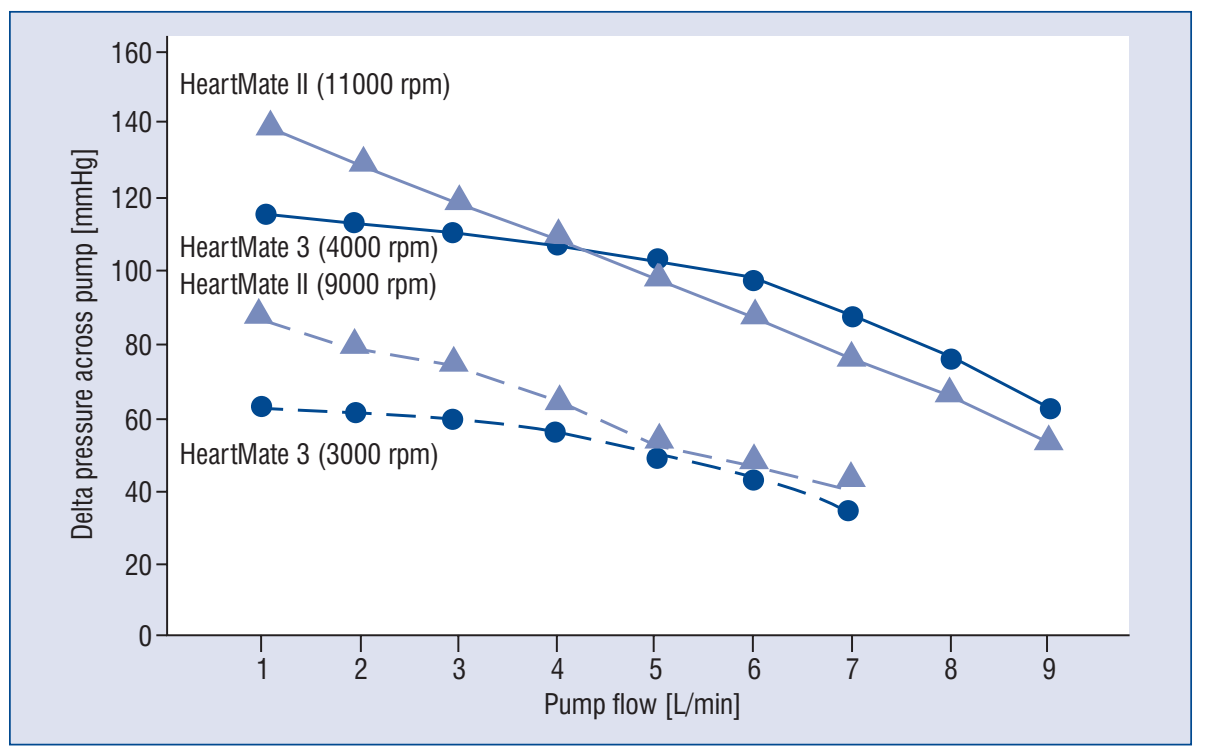

Figure 1. Comparison between delta pressure and pump flow with the axial flow left ventricular assist devices (LVAD) (HeartMate II) against the continuous flow LVAD (HeartMate 3).

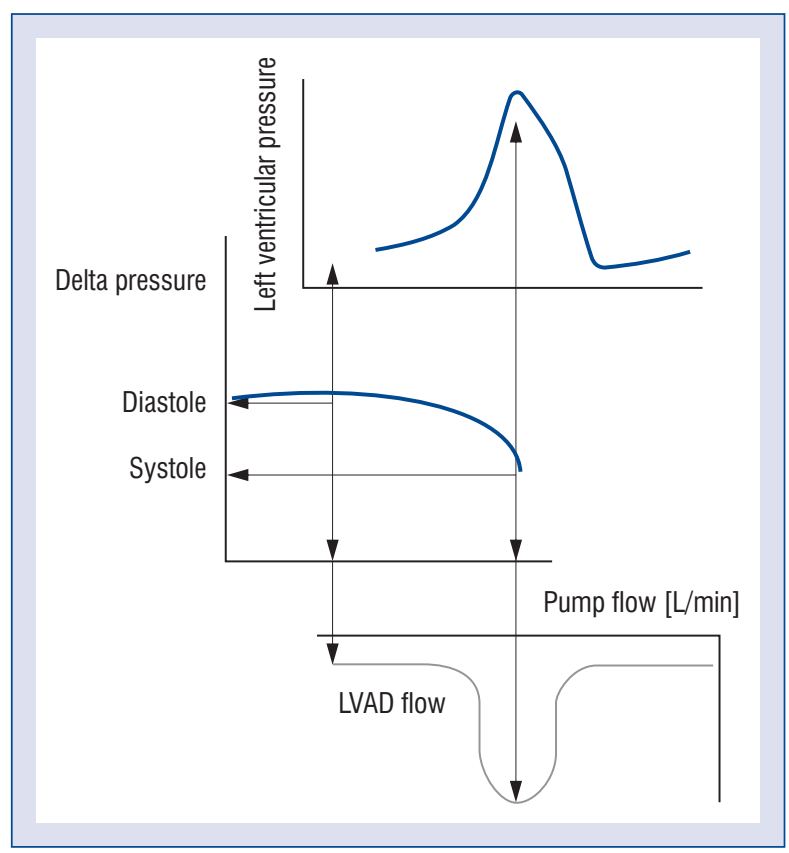

Figure 2. Effect of delta pressure in continuous-flow left ventricular assist devices (LVAD).

graft may be detached from the pump, allowing a pump replacement, if required, without a new re-anastomosis [19]. A pump cable called a "driveline" is permanently attached and tunneled through the abdominal tissue and exteriorized through a skin wound. It contains duplicate sets of three conductors: two for power and ground, and a third for communication. The "driveline" allows a con- nection between the external power system with the internal pump.

Blood flow through the centrifugal pump is directly proportional to pump speed and inversely related to the "delta pressure". Continuous flow through the pump occurs throughout the cardiac cycle; however, there are phasic changes in the pump flow, presenting higher flows during native cardiac systole than in diastole because the native LV contraction raises the intracardiac pressure more rapidly and thereby lowers the pressure gradient that the pump must overcome. These phasic changes in blood flow impart a pulse to the native circulation. In some circumstances in which there is an absence of effective native cardiac contraction, the flow through the LVAD is non-pulsatile [20].

As mentioned, the flow is determined by the pump speed, which is usually set above $4800 \mathrm{rpm}$. A recent paper showed that in a speed range of 5200 to $5600 \mathrm{rpm}, 81 \%$ of patients achieved optimal target hemodynamic parameters [21]. In general, if the speed is correctly set, the LVAD flow will be optimal to attain good organ perfusion, allowing the aortic valve to open at least one time in every three beats, leading to the creation of an aortic cusp lavage, maintaining a certain intrinsic cardiac output, and avoiding thrombus formation in the cusps and in the LV cavity [22,23].

If the pump is set to a very high speed, there is a greater pump flow to the ascending aorta, which can increase the afterload and keep the aortic pressure above the ventricular pressure even during systole. Consequently, the aortic valve remains 


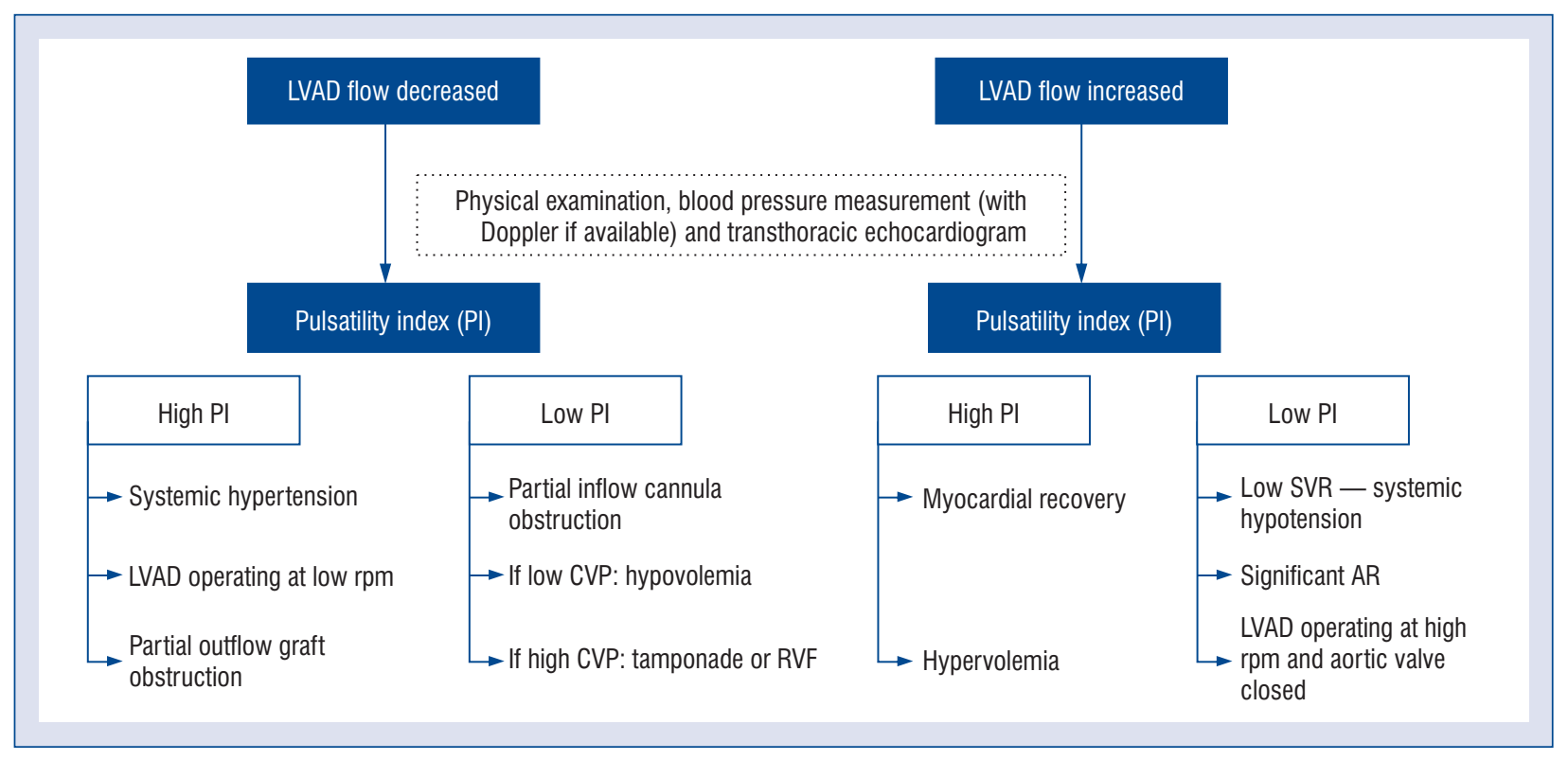

Figure 3. Algorithm of pulsatility index (PI) and flow values in continuous-flow left ventricular assist devices (LVAD); AR aortic regurgitation; CVP — central venous pressure; RVF — right ventricular failure; SVR — systemic vascular resistance.

closed in every cycle, leading to aortic insufficiency in the follow up. Moreover, the left cavity is unnecessarily unloaded and can collapse, with a potential risk of suction events and arrhythmias [24, 25].

Specifically, the HeartMate 3 system employs a feature called pulsatility index (PI) to recognize and avert this condition [11]. Also, this type of LVAD produces an artificial beat 30 times per minute, without any synchronization with the heart. When the degree of pulsatility measured in the waveform falls below a preset value, the system regards this as a risk of a suction event and automatically lowers the rotor speed to a preset low speed limit and then gradually returns the rotor to its original speed. PI values typically range from 1 to 10 . The value is directly related to the amount of assistance provided by the pump. Higher values indicate more ventricular filling and higher pulsatility, mimicking that the pump is providing less support to the LV. Lower values indicate less ventricular filling and lower pulsatility, showing that the pump is providing greater support and further unloading the ventricle. By the interrogation of PI and flow across the LVAD, the clinician can ascertain the presenting clinical scenario, as shown in Figure 3.

\section{Complications}

\section{Driveline infection}

Despite the advances in the fully electromagnetic levitation pump with the HeartMate 3 sys- tem, the requirement of a "driveline" to connect the pump with the system controller is an entry point that can promote infections by common skin microorganisms [26-28]. Infection is the secondmost frequent adverse event after bleeding in the first 3 months after LVAD implantation [29]. The largest proportion of LVAD patients presenting with infectious symptoms has a "driveline" infection (around 80\%) [30]. The "driveline" consists of two parts: the pump cable, which is inside the patient's body connected to the intrapericardial pump, and the modular cable, which comes from patient's abdomen and connects to the system controller. "Driveline" infections (Fig. 4A) were reported in $23 \%$ of patients at 2 years in the MOMENTUM 3 trial and in $16.7 \%$ of patients in the ADVANCE trial $[5,31]$. It is still a high proportion of patients, and this fact leads to significant comorbidity. Patients must receive a course of antibiotics, they can develop sepsis, and sometimes they require a surgical debridement. All these aspects mean they are frequently reviewed at the hospital and can be admitted several times due to these causes. The most common microorganisms are gram-positive bacteria, Staphylococcus spp. being the most prevalent (accounting around 50\% of total "driveline" infections [31]). Whether or not infections are related to thrombotic events is a matter of discussion [32,33]. One hypothesis is related to the fact that inflammatory response can promote platelet activation, altering coagulation 


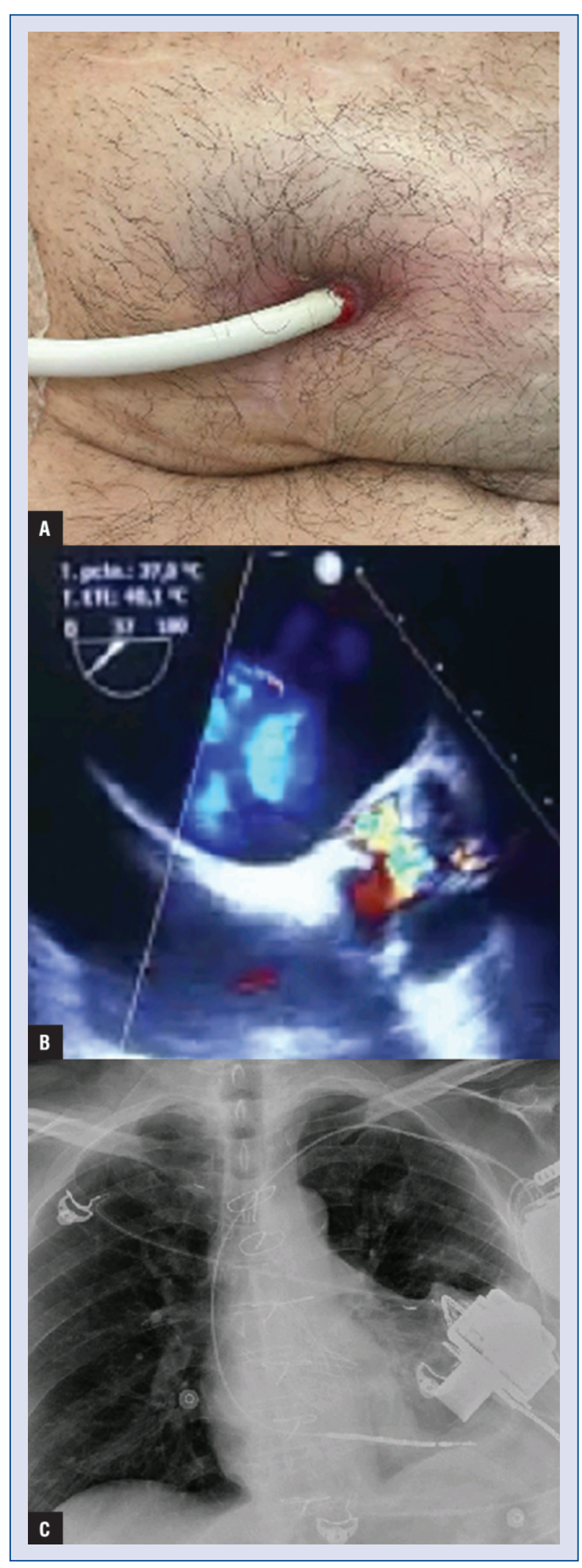

Figure 4. A. A "driveline" exit with signs of local infection (erythema and inflammation); B. Short-axis $30^{\circ}$ view with severe aortic regurgitation in a patient with a HeartMate 3; C. Chest X-ray of the same patient after transcatheter aortic valve replacement implantation. status [34]. According to some studies, infection is associated with an inflammatory status that can further promote higher rates of ischemic stroke and other prothrombotic complications [35].

For all these reasons, the "driveline" should be stabilized immediately after the device is placed and throughout the duration of support, and LVAD patients and relatives must be educated on self-care to minimize the risk of driveline infection $[36,37]$.

The evaluation of an LVAD "driveline" infection includes obtaining samples from the "driveline" exit, blood cultures, and preferably using an imaging technique such as computed tomography or positron emission tomography/computed tomography to rule out the presence of profound skin complications like an abdominal abscess [38]. The treatment usually includes intravenous antibiotics during admission, and once the patient is stabilized, switching to oral therapy can be considered, including a long course of suppression treatment in some cases $[28-40]$.

\section{Aortic regurgitation}

It is usually a long-term complication in patients on LVAD support (Fig. 4B). Around $30 \%$ of patients develop at least mild to moderate aortic regurgitation within the first year of LVAD support [41]. Its pathophysiology is multifactorial and mainly related to the afterload created by the flow released into the aorta. This can produce a reduced or an absent aortic valve opening, which can derange in a fusion of the valve commissures and a distortion of the aortic valve [42, 43]. Several strategies have been suggested to prevent this. First, according to current guidelines, the recommendation with pre-existing more than mild aortic regurgitation is to treat it during the LVAD surgery when feasible, usually by aortic valve replacement with a bioprosthesis [44]. Medical treatment of clinically symptomatic aortic regurgitation in LVAD patients includes diuretics and vasodilators, in order to reduce the LV filling pressures and to promote native forward flow [42, 43, 45]. When facing this complication, the clinician may be tempted to increase the LVAD speed with the purpose of a better LV unloading, but, unfortunately, higher speeds tend to increase the severity of the regurgitation and further perpetuate the aortic valve closure [46]. At this point, when the aortic regurgitation becomes evident in patients' hemodynamics and HF symptoms, surgical or transcatheter correction should be considered [47, 48]. In cases where the initial strategy was a bridge to transplantation, if there is no organ dysfunction 
present, an upgrade in the waiting list status and an urgent heart transplantation may be an option [41]. Because many LVAD patients are planned a destination therapy strategy and they gather significant comorbidities that render them high-risk patients for a reoperation, recent case series and isolated case reports suggest that transcatheter aortic valve replacement is a safe option to correct the aortic regurgitation (Fig. 4C) [48, 49]. The procedure must be planned carefully because calcified aortic annulus is normally absent, and the prosthesis can embolize [50-52].

\section{Right ventricular failure}

Right ventricular (RV) failure is the most threatening early complication after LVAD implantation. Its prevalence is variable between series, ranging from $15 \%$ to $50 \%$ [53]. It usually presents within 2 weeks after device implantation [54]. Cautious patient selection and a hemodynamic optimization before LVAD implantation must be made to prevent this [55]. Its pathophysiology comes from dynamic changes just after LVAD implantation, as it decompresses the LV causing a leftward shift of the interventricular septum, which results in a more spherical shape of the right ventricle. This may reduce the mechanical contractile properties of the RV free wall. Also, RV hemodynamics suddenly change because the chamber must accept a higher flow of preload. This complication carries a high risk of morbidity and mortality, prolonging the in-hospital stay and, when RV mechanical support is needed, raising the mortality rate to $40 \%$ [56]. Careful postoperative management is important, but identifying factors associated with adverse postoperative outcomes before LVAD implantation can be crucial [57]. In a recent metaanalysis, patients needing dialysis or another form of continuous renal replacement therapy at baseline and those on ventilatory support appeared to be correlated with risk of RV failure occurrence after LVAD implantation [53].

All patients must have complete imaging and hemodynamic assessment. Regarding echocardiographic parameters, longitudinal excursion of the right ventricle free wall and more than moderate $\mathrm{RV}$ dysfunction were the most frequent parameters associated with RV failure [3, 58, 59]. When talking about hemodynamics, central venous pressure and right ventricle working systolic index appear to be the predictors of RV failure [53, 60, 61].

Management of acute RV failure is challenging. It usually includes inotropes (milrinone, dobutamine, epinephrine, and isoproterenol) and RV afterload reduction with inhaled pulmonary vasodilators (nitric oxide, prostacyclin analogs, and milrinone). If pharmacologic therapy is not enough, early mechanical circulatory support should be initiated as soon as possible [62]. Survival to discharge is two-fold higher in patients who have received early planned RV assist device implantation compared to those who need it as rescue therapy [63].

\section{Ventricular arrhythmias}

Because the LV is supported by the pump, this complication is not usually a life-threatening situation. The most powerful predictor of post-LVAD ventricular arrhythmias is having experienced them before the LVAD implantation [64]. Despite the high incidence of ventricular arrhythmias in patients with LVAD, there is no common consensus on how to approach them. Usually, intervention with ablation must be performed in centers with experience. Intravenous amiodarone and sodium channel-blocking agents such as procainamide remain the preferred drug regimen in the short-term setting [65]. The usual source of ventricular arrhythmias is the surrounding area of the inflow cannula. Successful ablation has been described and must be achieved if antiarrhythmic drugs are not effective or hemodynamically instability occurs during episodes.

The most common presentation at the Emergency Department is with low flow alarms, and symptoms vary from dizziness to a feeling of fast heartbeat. Loss of consciousness is uncommon [26, 64, 66]. Regarding the need of implantable cardioverter-defibrillator (ICD) implantation, data are controversial. The common consensus is that shocks, both appropriate and inappropriate, have been associated with significant mortality and morbidity. The evidence on whether its implantation offers better survival was initially established with pulsatile devices $[67,68]$. Three series of around 100 patients each [69-71] reported that the presence of an active ICD was not associated with improved survival in patients with continuous-flow LVAD. A meta-analysis including 937 patients showed that ICD therapy was associated with decreased mortality, but this finding was not significant in patients with continuous-flow LVAD [72].

For this reason, several groups avoid its implantation after the LVAD procedure. In our opinion, the decision must be individualized, with stronger consideration if ventricular arrhythmias cannot be successfully ablated and in those patients with more hemodynamic compromise during episodes. 


\section{Pump thrombosis}

The MOMENTUM-3 trial showed a very low rate of pump exchange at 2 years with the HeartMate 3 device due to suspected pump thrombosis (2.3\%) [5]. With the new generation of magnetically levitated centrifugal pumps, this complication appears to become marginal in the near future. LVAD thrombosis may occur in the inflow cannula, in the pump or impeller, or in the outflow graft. Its presentation varies from cardiogenic shock to alarms in pump parameters (usually a raise in the pump power) [26, 27]. It is mandatory to perform laboratory tests (with lactate dehydrogenase, plasma-free hemoglobin, bilirubin, and urine test) if thrombosis suspicion is made [73]. A transthoracic echocardiogram cannot detect the presence of thrombi within the device, and they are rarely seen around the inflow cannula. The only finding can be a more dilated LV due to the absence of unloading and a wider opening aortic valve (if it was barely opening previously). Transthoracic or transesophageal echocardiograms are more useful if a ramp test is performed $[74,75]$. If the pump is working normally, the usual finding with a ramp test is a reduction in the $\mathrm{LV}$ end diastolic diameter and a closed aortic valve by increasing the pump speed. If this does not happen and laboratory tests and pump parameters are concordant with pump thrombosis, the diagnosis is more plausible. A chest computed tomography with contrast might be useful to assess the outflow graft [76]. Confirmatory diagnosis is made by pump exchange and thrombus visualization. Treatment varies from adjusting antithrombotic therapy initiating heparin or bivalirudin infusions in less severe cases to thrombolysis or emergent surgical pump replacement if the patient is in cardiogenic shock [77, 78].

\section{Neurological events}

Together with "driveline" infections, neurological events have been the Achilles heel of continuous-flow LVADs, impacting the results in the medium- and long-term follow-up and conditioning a deterioration in the quality of life and an increase in the number of visits to the hospital. Stroke is the major cause of death between 6 and 24 months after LVAD implantation and occurs at a rate of $8.7 \%$ per year [79]. This incidence has been minimized in the recent 2-year outcome of the MOMEMTUM-3 trial with a total of 22 strokes occurring in 19 patients in the HM3 group (10.1\%), contrasting with the 43 events that occurred in $33(19.2 \%)$ patients in the HMII group (hazard ratio [HR] 0.47; $\mathrm{p}=0.02$ ) $[5,80]$. Ischemic strokes usually result from embol- ic sources on the aortic valve, the inflow cannula, or intracardiac chambers. A closed aortic valve has been described as a predictor of pump thrombosis and ischemic strokes [22]. Hemorrhagic strokes may occur mainly secondarily to hypertension or coagulopathy. A recent publication has shown an international normalized ratio between 1.5 and 2 to be safe regarding pump thrombosis, possibly minimizing the risk of hemorrhagic strokes [81].

Neurological events are the leading primary cause of death in the INTERMACS registry and may also compromise patients' candidacy for heart transplantation [82].

\section{Gastrointestinal bleeding}

The risk of bleeding in the setting of continuous-flow LVAD is multifactorial and mainly related to anticoagulation and antiplatelet therapy and the effect of the continuous flow in the consumption of von Willebrand factor and angiogenesis [83].

Importantly, some studies have shown that many platelet abnormalities precede the LVAD implantation, such as an impaired ristocetin-induced platelet aggregation and a decreased thrombopoietin production and uremia due to hepatorenal syndrome [84].

Minimizing antithrombotic therapy is key for this kind of technology because acquired von Willebrand syndrome is prevalent in LVAD patients [85] and can be detected as early as 30 days post implantation [86]. Finally, acquired von Willebrand syndrome leads to angiodysplasias formation and is itself pro-angiogenic, resulting in the main mechanism of nasal and gastrointestinal bleeding in LVAD patients $[83,86]$.

The treatment should focus on minimizing the antithrombotic therapy, which seems to be safe according to a recent study [81]. A somatostatin analog, octreotide, is currently used as a first-line therapy, especially when angiodysplasias are diagnosed. Thalidomide and desmopressin have also been used in various small studies. Finally, the use of von Willebrand factor concentrate has also been proposed in severe bleeding cases [83].

\section{Future directions}

Despite the great advances made in the field of mechanical circulatory support in recent decades, there are still considerable obstacles that affect clinical outcomes and patient's quality of life. Therefore, the immediate future of LVAD implantation must be aimed at solving these drawbacks.

First, perioperative complications can be reduced by performing minimally invasive surgeries (MIS), which have been possible thanks to the technological 


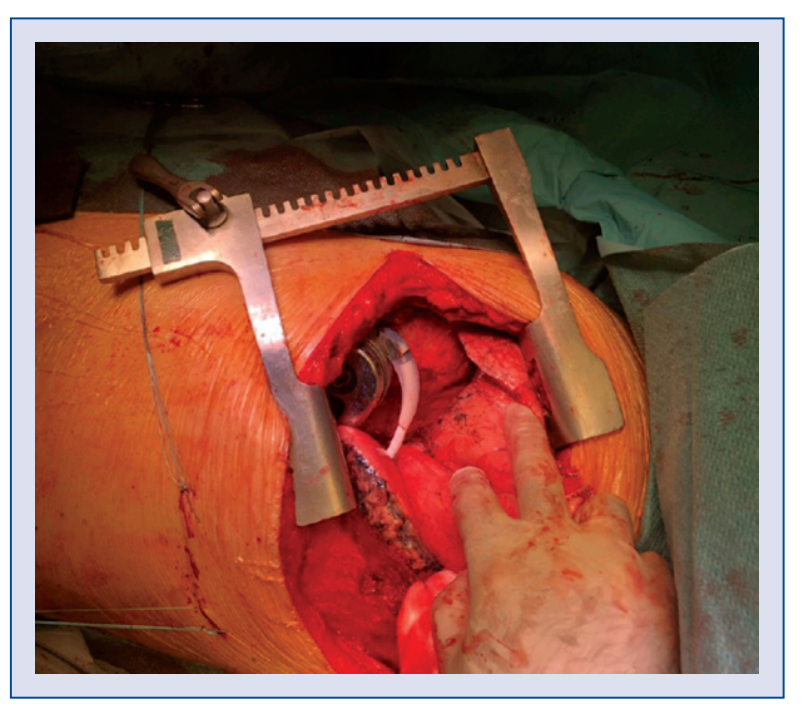

Figure 5. Left thoracotomy access to implant a left ventricular assist device.

improvements made, mainly with the progressive reduction in the size of the different devices. To date, several approaches have been described for MIS, but all of them converge in the performance of a left lateral thoracotomy for the inflow cannula implantation in the LV apex, as shown in Figure 5.

The differences between the currently described approaches lie on the technique for the outflow cannula implantation: superior J-hemisternotomy, right superior minithoracotomy (secondthird intercostal space), left lateral thoracotomy with the anastomosis in the descending aorta, and direct exposure of the left subclavian artery [87-89]. This type of sternal-sparing surgery has shown a good efficacy and safety profile in several single-center series and in clinical trials. Thus, in the LATERAL trial, which included 144 patients who underwent an LVAD HeartWare (HVAD, HeartWare Inc., Miami Lakes, USA) implantation as a bridge to transplantation through superior hemisternotomy and left lateral thoracotomy, $88 \%$ of the patients were alive with the originally implanted device at 6 months and free of disabling stroke, heart transplant, or explant for recovery [90]. Overall survival was $89 \%$ at 1 year and $87 \%$ at 2 years, with a favorable rate of adverse events, mainly from the first 30 days post implantation [91]. Other additional benefits of MIS are as follows: the risk reduction of perioperative bleeding and blood product requirements, which subsequently reduces the risk of allosensitization; the reduction in the cardiopulmonary bypass time and hospital admission; keeping the main body of the sternum intact in the case of a future heart transplant/ /reintervention; and, as it has been suggested, a reduction in the risk of $\mathrm{RV}$ failure by preserving the adjacent pericardium to the free wall of the right ventricle [90, 92-95]. Recent data have shown how these techniques have been progressively implemented, currently reaching up to $70 \%$ of implants in highly experienced centers [95]. However, given the aforementioned benefits, we must strive to promote the necessary training and education to continue expanding MIS.

Another drawback still present is the need of a percutaneous "driveline" to supply the energy for their correct operation, which not only limits the patient's quality of life but also represents a constant risk of device infection. Hence, the need arises to develop fully implantable devices with wireless power transmission systems. However, to date, few devices have gained sufficient clinical relevance, such as the Arrow-Lionheart and the Abiocor Total Artificial Heart [97, 98]. The most recent of these devices to be clinically tested has been the Leviticus FiVAD ${ }^{\mathrm{TM}}$ (Leviticus Cardio Ltd., Petah Tikva, Israel), which uses a novel wireless power transmission system called Coplanar Power Transmission. The Coplanar Power Transmission consists of two coils: an internal one located in the lower part of the right pleural cavity and an external one mounted on a power transmission belt that transmits energy by induction, thus allowing the charging of the internal battery/controller, which is located in the right lateral chest wall, showing a duration of 6 to 8 hours between loads. This system is designed to be compatible with all commercially available LVAD, and to date it has been used successfully in 2 patients coupled to the Jarvik $2000^{\circledR}$ LVAD (Jarvik Heart, Inc., NY, USA) [99].

Therefore, we must persevere in the development of wireless transmission systems for the energy supply and the miniaturization of LVADs to allow full implantation through minimally invasive surgical approaches so as to reduce the risk of device infections. However, the Medtronic company sadly recently discontinued the production of HVAD for future implantations, resulting in the demise of a competitive market, which raises concerns about achieving these priority goals [100].

\section{Acknowledgments}

The authors would like to thank Alejandro Carta Bergaz for his assistance in the development of the central illustration.

Conflict of interest: None declared 


\section{References}

1. McDonagh TA, Metra M, Adamo M, et al. ESC Scientific Document Group. 2021 ESC Guidelines for the diagnosis and treatment of acute and chronic heart failure. Eur Heart J. 2021; 36: 3599-3726, doi: 10.1093/eurheartj/ehab368, indexed in Pubmed: 34447992.

2. Maddox TM, Januzzi JL, Allen LA, et al. 2021 Update to the 2017 ACC Expert Consensus Decision Pathway for Optimization of Heart Failure Treatment: Answers to 10 Pivotal Issues About Heart Failure With Reduced Ejection Fraction: A Report of the American College of Cardiology Solution Set Oversight Committee. J Am Coll Cardiol. 2021; 77(6): 772-810, doi: 10.1016/j. jacc.2020.11.022, indexed in Pubmed: 33446410.

3. Gustafsson F, Rogers JG. Left ventricular assist device therapy in advanced heart failure: patient selection and outcomes. Eur J Heart Fail. 2017; 19(5): 595-602, doi: 10.1002/ejhf.779, indexed in Pubmed: 28198133.

4. Rose E, Gelijns A, Moskowitz A, et al. Long-Term Use of a Left Ventricular Assist Device for End-Stage Heart Failure. N Engl J Med. 2001; 345(20): 1435-1443, doi: 10.1056/nejmoa012175.

5. Mehra MR, Uriel N, Naka Y, et al. A fully magnetically levitated left ventricular assist device - final report. N Engl J Med. 2019; 380(17): 1618-1627, doi: 10.1056/NEJMoa1900486, indexed in Pubmed: 30883052.

6. Metra M, Eichhorn E, Abraham WT, et al. Effects of low-dose oral enoximone administration on mortality, morbidity, and exercise capacity in patients with advanced heart failure: the randomized, double-blind, placebo-controlled, parallel group ESSENTIAL trials. Eur Heart J. 2009; 30(24): 3015-3026, doi: 10.1093/ eurheartj/ehp338, indexed in Pubmed: 19700774.

7. Lindenfeld J, Feldman AM, Saxon L, et al. Effects of cardiac resynchronization therapy with or without a defibrillator on survival and hospitalizations in patients with New York Heart Association class IV heart failure. Circulation. 2007; 115(2): 204-212, doi: 10.1161/CIRCULATIONAHA.106.629261, indexed in Pubmed: 17190867.

8. Goldstein DJ, Meyns B, Xie R, et al. Third annual report from the ISHLT mechanically assisted circulatory support registry: a comparison of centrifugal and axial continuous-flow left ventricular assist devices. J Heart Lung Transplant. 2019; 38(4): 352-363, doi: 10.1016/j.healun.2019.02.004, indexed in Pubmed: 30945637.

9. Netuka I, Sood P, Pya Y, et al. Fully magnetically levitated left ventricular assist system for treating advanced HF: a multicenter study. J Am Coll Cardiol. 2015; 66(23): 2579-2589, doi: 10.1016/j.jacc.2015.09.083, indexed in Pubmed: 26670056.

10. Zimpfer D, Netuka I, Schmitto JD, et al. Multicentre clinical trial experience with the HeartMate 3 left ventricular assist device: 30-day outcomes. Eur J Cardiothorac Surg. 2016; 50(3): 548-554, doi: 10.1093/ejcts/ezw169, indexed in Pubmed: 27436871.

11. Krabatsch T, Netuka I, Schmitto JD, et al. Heartmate 3 fully magnetically levitated left ventricular assist device for the treatment of advanced heart failure -1 year results from the Ce mark trial. J Cardiothorac Surg. 2017; 12(1): 23, doi: 10.1186/s13019017-0587-3, indexed in Pubmed: 28376837.

12. Schmitto JD, Pya Y, Zimpfer D, et al. Long-term evaluation of a fully magnetically levitated circulatory support device for advanced heart failure-two-year results from the HeartMate 3CE Mark Study. Eur J Heart Fail. 2019; 21(1): 90-97, doi: 10.1002/ejhf.1284, indexed in Pubmed: 30052304.
13. Bourque K, Cotter C, Dague C, et al. Design rationale and preclinical evaluation of the heartmate 3 left ventricular assist system for hemocompatibility. ASAIO J. 2016; 62(4): 375-383, doi: 10.1097/MAT.0000000000000388, indexed in Pubmed: 27195742.

14. Lim HS, Howell N, Ranasinghe A. The physiology of continuous-flow left ventricular assist devices. J Card Fail. 2017; 23(2): 169-180, doi: 10.1016/j.cardfail.2016.10.015, indexed in Pubmed: 27989869.

15. Miller LW, Rogers JG. Evolution of left ventricular assist device therapy for advanced heart failure: a review. JAMA Cardiol. 2018; 3(7): 650-658, doi: 10.1001/jamacardio.2018.0522, indexed in Pubmed: 29710092.

16. Potapov EV, Netuka I, Kaufmann F, et al. Strategy for surgical correction and mitigation of outflow graft twist with a centrifugal-flow left ventricular assist system. J Heart Lung Transplant. 2018; 37(5): 670-673, doi: 10.1016/j.healun.2018.03.014, indexed in Pubmed: 29673654.

17. Abbott Recalls the HeartMate 3TM Left Ventricular Assist System Due to Potential Malfunction that may Lead to Graft Occlusion. https://www.fda.gov/medical-devices/medical-device-recalls/abbott-recalls-heartmate-3tm-leftventricular-assist-system-due-potential malfunction-may-lead-graft.

18. Rivas-Lasarte M, Scatola A, Sims DB, et al. A new twist to HeartMate 3 low flow alarms. Rev Esp Cardiol (Engl Ed). 2021; 74(4): 349-351, doi: 10.1016/j.rec.2020.09.013, indexed in Pubmed: 33097443.

19. Hanke JS, Rojas SV, Dogan G, et al. First series of left ventricular assist device exchanges to HeartMate 3. Eur J Cardiothorac Surg. 2017; 51(5): 887-892, doi: 10.1093/ejcts/ezx010, indexed in Pubmed: 28329060.

20. Saito S, Nishinaka T. Chronic nonpulsatile blood flow is compatible with normal end-organ function: implications for LVAD development. J Artif Organs. 2005; 8(3): 143-148, doi: 10.1007/ s10047-005-0295-y, indexed in Pubmed: 16235030.

21. Uriel N, Adatya S, Malý J, et al. Clinical hemodynamic evaluation of patients implanted with a fully magnetically levitated left ventricular assist device (HeartMate 3). J Heart Lung Transplant. 2017; 36(1): 28-35, doi: 10.1016/j.healun.2016.07.008, indexed in Pubmed: 27773456.

22. Dobarro D, Urban M, Booth K, et al. Impact of aortic valve closure on adverse events and outcomes with the HeartWare ventricular assist device. J Heart Lung Transplant. 2017; 36(1): 42-49, doi: 10.1016/j.healun.2016.08.006, indexed in Pubmed: 27776988.

23. John R, Mantz K, Eckman P, et al. Aortic valve pathophysiology during left ventricular assist device support. J Heart Lung Transplant. 2010; 29(12): 1321-1329, doi: 10.1016/j.healun.2010.06.006, indexed in Pubmed: 20674397.

24. Bartoli CR, Giridharan GA, Litwak KN, et al. Hemodynamic responses to continuous versus pulsatile mechanical unloading of the failing left ventricle. ASAIO J. 2010; 56(5): 410-416, doi: 10.1097/MAT.0b013e3181e7bf3c, indexed in Pubmed: 20613490.

25. Healy C, Viles-Gonzalez JF, Sacher F, et al. Management of ventricular arrhythmias in patients with mechanical ventricular support devices. Curr Cardiol Rep. 2015; 17(8): 59, doi: 10.1007/ s11886-015-0617-5, indexed in Pubmed: 26072439.

26. Long B, Robertson J, Koyfman A, et al. Left ventricular assist devices and their complications: A review for emergency clinicians. Am J Emerg Med. 2019; 37(8): 1562-1570, doi: 10.1016/j. ajem.2019.04.050, indexed in Pubmed: 31072684. 
27. Kiamanesh O, Kaan A, Toma M. Medical management of left ventricular assist device patients: a practical guide for the nonexpert clinician. Can J Cardiol. 2020; 36(2): 205-215, doi: 10.1016/j.cjca.2019.09.020, indexed in Pubmed: 31879052.

28. O'Horo JC, Abu Saleh OM, Stulak JM, et al. Left ventricular assist device infections: a systematic review. ASAIO J. 2018; 64(3): 287-294, doi: 10.1097/MAT.0000000000000684, indexed in Pubmed: 29095732.

29. Schlöglhofer T, Michalovics P, Riebandt J, et al. Left ventricular assist device driveline infections in three contemporary devices. Artif Organs. 2021; 45(5): 464-472, doi: 10.1111/aor.13843, indexed in Pubmed: 33052592.

30. Blanco-Guzman MO, Wang X, Vader JM, et al. Epidemiology of left ventricular assist device infections: findings from a large nonregistry cohort. Clin Infect Dis. 2021; 72(2): 190-197, doi: 10.1093/cid/ciaa011, indexed in Pubmed: 31925953.

31. John R, Aaronson KD, Pae WE, et al. HeartWare Bridge to Transplant ADVANCE Trial Investigators. Drive-line infections and sepsis in patients receiving the HVAD system as a left ventricular assist device. J Heart Lung Transplant. 2014; 33(10): 1066-1073, doi: 10.1016/j.healun.2014.05.010, indexed in Pubmed: 25087103.

32. Shah P, Mehta VM, Cowger JA, et al. Diagnosis of hemolysis and device thrombosis with lactate dehydrogenase during left ventricular assist device support. J Heart Lung Transplant. 2014; 33(1): 102-104, doi: 10.1016/j.healun.2013.07.013, indexed in Pubmed: 23968811.

33. Uriel N, Han J, Morrison KA, et al. Device thrombosis in HeartMate II continuous-flow left ventricular assist devices: a multifactorial phenomenon. J Heart Lung Transplant. 2014; 33(1): 51-59, doi: 10.1016/j.healun.2013.10.005, indexed in Pubmed: 24290832.

34. Schrottmaier WC, Kral JB, Zeitlinger M, et al. Platelet activation at the onset of human endotoxemia is undetectable in vivo. Platelets. 2016; 27(5): 479-483, doi: 10.3109/09537104.2015.1119814, indexed in Pubmed: 26764560.

35. Park SJ, Milano CA, Tatooles AJ, et al. Outcomes in advanced heart failure patients with left ventricular assist devices for destination therapy. Circ Heart Fail. 2012; 5(2): 241-248, doi: 10.1161/CIRCHEARTFAILURE.111.963991, indexed in Pubmed: 22282104.

36. Feldman D, Pamboukian SV, Teuteberg JJ, et al. The 2013 International Society for Heart and Lung Transplantation Guidelines for mechanical circulatory support: executive summary. J Heart Lung Transplant. 2013; 32(2): 157-187, doi: 10.1016/j. healun.2012.09.013, indexed in Pubmed: 23352391.

37. Cagliostro B, Levin AP, Fried J, et al. Continuous-flow left ventricular assist devices and usefulness of a standardized strategy to reduce drive-line infections. J Heart Lung Transplant. 2016; 35(1): 108-114, doi: 10.1016/j.healun.2015.06.010, indexed in Pubmed: 26476767.

38. Kimura Y, Seguchi O, Mochizuki H, et al. Role of Gallium-SPECT-CT in the Management of Patients With Ventricular Assist Device-Specific Percutaneous Driveline Infection. J Card Fail. 2019; 25(10): 795-802, doi: 10.1016/j.cardfail.2019.08.009, indexed in Pubmed: 31454687.

39. Koval CE, Stosor V. AST ID Community of Practice. Ventricular assist device-related infections and solid organ transplantation: Guidelines from the American Society of Transplantation Infectious Diseases Community of Practice. Clin Transplant. 2019; 33(9): e13552, doi: 10.1111/ctr.13552, indexed in Pubmed: 30924952.
40. Aslam S. Ventricular assist device infections. Cardiol Clin. 2018; 36(4): 507-517, doi: 10.1016/j.ccl.2018.06.005, indexed in Pubmed: 30297068.

41. Truby LK, Garan AR, Givens RC, et al. Aortic insufficiency during contemporary left ventricular assist device support: analysis of the INTERMACS registry. JACC Heart Fail. 2018; 6(11): 951-960, doi: 10.1016/j.jchf.2018.07.012, indexed in Pubmed: 30384913 .

42. Jorde UP, Uriel N, Nahumi N, et al. Prevalence, significance, and management of aortic insufficiency in continuous flow left ventricular assist device recipients. Circ Heart Fail. 2014; 7(2): 310-319, doi: 10.1161/CIRCHEARTFAILURE.113.000878, indexed in Pubmed: 24415682.

43. Pak SW, Uriel N, Takayama H, et al. Prevalence of de novo aortic insufficiency during long-term support with left ventricular assist devices. J Heart Lung Transplant. 2010; 29(10): 1172 1176, doi: 10.1016/j.healun.2010.05.018, indexed in Pubmed: 20619680.

44. Kirklin JK, Pagani FD, Goldstein DJ, et al. Editors, Contributing Authors, Reviewers. American Association for Thoracic Surgery/International Society for Heart and Lung Transplantation guidelines on selected topics in mechanical circulatory support. J Heart Lung Transplant. 2020; 39(3): 187-219, doi: 10.1016/j. healun.2020.01.1329, indexed in Pubmed: 31983666.

45. Imamura T, Narang N, Kim G, et al. Impact of worsening of aortic insufficiency during HeartMate 3 LVAD support. Artif Organs. 2021; 45(3): 297-302, doi: 10.1111/aor.13825, indexed in Pubmed: 33098153.

46. Kiamanesh O, Kaan A, Toma M. Medical management of left ventricular assist device patients: a practical guide for the nonexpert clinician. Can J Cardiol. 2020; 36(2): 205-215, doi: 10.1016/j.cjca.2019.09.020, indexed in Pubmed: 31879052.

47. Bhagra SK, Pettit S, Parameshwar J. Implantable left ventricular assist device: indications, eligibility and current outcomes. Heart. 2021 [Epub ahead of print], doi: 10.1136/heartjnl-2020-317886, indexed in Pubmed: 34099466.

48. Yehya A, Rajagopal V, Meduri C, et al. Short-term results with transcatheter aortic valve replacement for treatment of left ventricular assist device patients with symptomatic aortic insufficiency. J Heart Lung Transplant. 2019; 38(9): 920-926, doi: 10.1016/j.healun.2019.03.001, indexed in Pubmed: 30898555.

49. Fried JA, Nazif TM, Colombo PC. A new frontier for TAVR: Aortic insufficiency in CF-LVAD patients. J Heart Lung Transplant. 2019; 38(9): 927-929, doi: 10.1016/j.healun.2019.06.024, indexed in Pubmed: 31495409.

50. van der Werf HW, Schurer RAj, Vonck TE, et al. Emergency transcatheter aortic valve implantation in patients with severe aortic regurgitation and a left ventricle assist device: A case report and systematic review. Eur Heart J Acute Cardiovasc Care. 2017; 6(8): 719-727, doi: 10.1177/2048872616652310, indexed in Pubmed: 27245700.

51. Parikh KS, Mehrotra AK, Russo MJ, et al. Percutaneous transcatheter aortic valve closure successfully treats left ventricular assist device-associated aortic insufficiency and improves cardiac hemodynamics. JACC Cardiovasc Interv. 2013; 6(1): 84-89, doi: 10.1016/j.jcin.2012.08.021, indexed in Pubmed: 23347865.

52. Cowger J, Rao V, Massey T, et al. Comprehensive review and suggested strategies for the detection and management of aortic insufficiency in patients with a continuous-flow left ventricular assist device. J Heart Lung Transplant. 2015; 34(2): 149-157, doi: 10.1016/j.healun.2014.09.045, indexed in Pubmed: 25511746. 
53. Bellavia D, Iacovoni A, Scardulla C, et al. Prediction of right ventricular failure after ventricular assist device implant: systematic review and meta-analysis of observational studies. Eur J Heart Fail. 2017; 19(7): 926-946, doi: 10.1002/ejhf.733, indexed in Pubmed: 28371221.

54. Cogswell R, John R, Shaffer A. Right ventricular failure after left ventricular assist device. Cardiol Clin. 2020; 38(2): 219-225, doi: 10.1016/j.ccl.2020.01.007, indexed in Pubmed: 32284098.

55. Benjamin MM, Sundararajan S, Sulaiman S, et al. Association of preoperative duration of inotropy on prevalence of right ventricular failure following LVAD implantation. ESC Heart Fail. 2020; 7(4): 1949-1955, doi: 10.1002/ehf2.12791, indexed in Pubmed: 32526807.

56. Lampert BC, Teuteberg JJ. Right ventricular failure after left ventricular assist devices. J Heart Lung Transplant. 2015; 34(9): 1123-1130, doi: 10.1016/j.healun.2015.06.015, indexed in Pubmed: 26267741.

57. Turner KR. Right ventricular failure after left ventricular assist device placement-the beginning of the end or just another challenge? J Cardiothorac Vasc Anesth. 2019; 33(4): 1105-1121, doi: 10.1053/j.jvca.2018.07.047, indexed in Pubmed: 30197170.

58. Ruiz-Cano MJ, Morshuis M, Koster A, et al. Risk factors of early right ventricular failure in patients undergoing LVAD implantation with intermediate Intermacs profile for advanced heart failure. J Card Surg. 2020; 35(8): 1832-1839, doi: 10.1111/ jocs.14696, indexed in Pubmed: 32557925.

59. Ali HJR, Kiernan MS, Choudhary G, et al. Right ventricular failure post-implantation of left ventricular assist device: prevalence, pathophysiology, and predictors. ASAIOJ.2020; 66(6): 610-619, doi: 10.1097/MAT.0000000000001088, indexed in Pubmed: 31651460.

60. Lampert BC, Teuteberg JJ. Right ventricular failure after left ventricular assist devices. J Heart Lung Transplant. 2015; 34(9): 1123-1130, doi: 10.1016/j.healun.2015.06.015, indexed in Pubmed: 26267741.

61. Raina A, Patarroyo-Aponte M. Prevention and treatment of right ventricular failure during left ventricular assist device therapy. Crit Care Clin. 2018; 34(3): 439-452, doi: 10.1016/j. ccc.2018.03.001, indexed in Pubmed: 29907275.

62. Mondal S, Sankova S, Lee K, et al. Intraoperative and early postoperative management of patients undergoing minimally invasive left ventricular assist device implantation. J Cardiothorac Vasc Anesth. 2021; 35(2): 616-630, doi: 10.1053/j.jvca.2020.04.015, indexed in Pubmed: 32505605.

63. Fitzpatrick JR, Frederick JR, Hiesinger W, et al. Early planned institution of biventricular mechanical circulatory support results in improved outcomes compared with delayed conversion of a left ventricular assist device to a biventricular assist device. J Thorac Cardiovasc Surg. 2009; 137(4): 971-977, doi: 10.1016/j. jtcvs.2008.09.021, indexed in Pubmed: 19327526.

64. Gopinathannair R, Cornwell WK, Dukes JW, et al. Device therapy and arrhythmia management in left ventricular assist device recipients: a scientific statement from the american heart association. Circulation. 2019; 139(20): e967-e989, doi: 10.1161/ CIR.0000000000000673, indexed in Pubmed: 30943783.

65. Caraang C, Lanier GM, Gass A, et al. Left ventricular assist device in older adults. Heart Fail Clin. 2017; 13(3): 619-632, doi: 10.1016/j.hfc.2017.02.013, indexed in Pubmed: 28602376.

66. Bohonos CJ, Bechtum EL, Luckhardt AJ, et al. Ventricular tachycardia and preload deficiency post LVAD: the importance of integrated assessment. Heart Lung. 2020; 49(5): 481-487, doi: 10.1016/j.hrtlng.2020.03.020, indexed in Pubmed: 32334843.
67. Cantillon DJ, Tarakji KG, Kumbhani DJ, et al. Improved survival among ventricular assist device recipients with a concomitant implantable cardioverter-defibrillator. Heart Rhythm. 2010; 7(4): 466-471, doi: 10.1016/j.hrthm.2009.12.022, indexed in Pubmed: 20178869.

68. Refaat MM, Tanaka T, Kormos RL, et al. Survival benefit of implantable cardioverter-defibrillators in left ventricular assist device-supported heart failure patients. J Card Fail. 2012; 18(2): 140-145, doi: 10.1016/j.cardfail.2011.10.020, indexed in Pubmed: 22300782.

69. Enriquez AD, Calenda B, Miller MA, et al. The role of implantable cardioverter-defibrillators in patients with continuous flow left ventricular assist devices. Circ Arrhythm Electrophysiol. 2013; 6(4): 668-674, doi: 10.1161/CIRCEP.113.000457, indexed in Pubmed: 23873139.

70. Garan AR, Yuzefpolskaya M, Colombo PC, et al. Ventricular arrhythmias and implantable cardioverter-defibrillator therapy in patients with continuous-flow left ventricular assist devices: need for primary prevention? J Am Coll Cardiol. 2013; 61(25): 2542-2550, doi: 10.1016/j.jacc.2013.04.020, indexed in Pubmed: 23643502.

71. Lee W, Tay A, Subbiah RN, et al. Impact of implantable cardioverter defibrillators on survival of patients with centrifugal left ventricular assist devices. Pacing Clin Electrophysiol. 2015; 38(8): 925-933, doi: 10.1111/pace.12654, indexed in Pubmed: 25940215.

72. Vakil K, Kazmirczak F, Sathnur N, et al. Implantable cardioverter-defibrillator use in patients with left ventricular assist devices: a systematic review and meta-analysis. JACC Heart Fail. 2016; 4(10): 772-779, doi: 10.1016/j.jchf.2016.05.003, indexed in Pubmed: 27395347.

73. Bartoli CR, Ghotra AS, Pachika AR, et al. Hematologic markers better predict left ventricular assist device thrombosis than echocardiographic or pump parameters. Thorac Cardiovasc Surg. 2014; 62(5): 414-418, doi: 10.1055/s-0034-1376891, indexed in Pubmed: 24995532.

74. Adatya S, Holley CT, Roy SS, et al. Echocardiographic Ramp test for continuous-flow left ventricular assist devices: do loading conditions matter? JACC Heart Fail. 2015; 3(4): 291-299, doi: 10.1016/j.jchf.2014.11.006, indexed in Pubmed: 25770403.

75. Kato TS, Colombo PC, Nahumi N, et al. Value of serial echo-guided ramp studies in a patient with suspicion of device thrombosis after left ventricular assist device implantation. Echocardiography. 2014; 31(1): E5-E9, doi: 10.1111/echo.12379, indexed in Pubmed: 24063315.

76. Barac YD, Nevo A, Schroder JN, et al. LVAD outflow graft role in pump thrombosis. ASAIO J. 2020; 66(2): 128-131, doi: 10.1097/ MAT.0000000000000936, indexed in Pubmed: 30585873.

77. Stulak JM, Sharma S, Maltais S. Management of pump thrombosis in patients with left ventricular assist devices. Am J Cardiovasc Drugs. 2015; 15(2): 89-94, doi: 10.1007/s40256-014-0102-3, indexed in Pubmed: 25567787.

78. Hanke JS, Dogan G, Wert L, et al. Left ventricular assist device exchange for the treatment of HeartMate II pump thrombosis. J Thorac Dis. 2018; 10(Suppl 15): S1728-S1736, doi: 10.21037/ jtd.2018.01.115, indexed in Pubmed: 30034845.

79. Giede-Jeppe A, Roeder SS, Macha K, et al. Management of stroke in patients with left ventricular assist devices. J Stroke Cerebrovasc Dis. 2020; 29(11): 105166, doi: 10.1016/j.jstrokecerebrovasdis.2020.105166, indexed in Pubmed: 33066940. 
80. Kuśmierczyk M, Różański J, Zembala M, et al. Heart failure in Poland: left ventricular assist device destination therapy and other challenges of interventional cardiology and cardiac surgery. Cardiol J. 2020; 27(6): 693-704, doi: 10.5603/CJ.a2020.0148, indexed in Pubmed: 33140383.

81. Netuka I, Ivák P, Tučanová $Z$, et al. Evaluation of low-intensity anti-coagulation with a fully magnetically levitated centrifugal-flow circulatory pump-the MAGENTUM 1 study. J Heart Lung Transplant. 2018; 37(5): 579-586, doi: 10.1016/j.healun.2018.03.002, indexed in Pubmed: 29655662.

82. Kadakkal A, Najjar SS. Neurologic events in continuous-flow left ventricular assist devices. Cardiol Clin. 2018; 36(4): 531-539, doi: 10.1016/j.ccl.2018.06.007, indexed in Pubmed: 30297070.

83. Kataria R, Jorde UP. Gastrointestinal bleeding during continuous-flow left ventricular assist device support: state of the field. Cardiol Rev. 2019; 27(1): 8-13, doi: 10.1097/ CRD.0000000000000212, indexed in Pubmed: 30520778.

84. Klovaite J, Gustafsson F, Mortensen SA, et al. Severely impaired von Willebrand factor-dependent platelet aggregation in patients with a continuous-flow left ventricular assist device (HeartMate II). J Am Coll Cardiol. 2009; 53(23): 2162-2167, doi: 10.1016/j. jacc.2009.02.048, indexed in Pubmed: 19497443.

85. Sakatsume Ko, Saito K, Akiyama M, et al. Association between the severity of acquired von Willebrand syndrome and gastrointestinal bleeding after continuous-flow left ventricular assist device implantation. Eur J Cardiothorac Surg. 2018; 54(5): 841-846, doi: 10.1093/ejcts/ezy172, indexed in Pubmed: 29741685.

86. Crow S, Chen D, Milano C, et al. Acquired von Willebrand syndrome in continuous-flow ventricular assist device recipients. Ann Thorac Surg. 2010; 90(4): 1263-9; discussion 1269, doi: 10.1016/j.athoracsur.2010.04.099, indexed in Pubmed: 20868825.

87. Schmitto JD, Molitoris U, Haverich A, et al. Implantation of a centrifugal pump as a left ventricular assist device through a novel, minimized approach: upper hemisternotomy combined with anterolateral thoracotomy. J Thorac Cardiovasc Surg. 2012; 143(2): 511-513, doi: 10.1016/j.jtcvs.2011.07.046, indexed in Pubmed: 21903225

88. Maltais S, Davis ME, Haglund N. Minimally invasive and alternative approaches for long-term LVAD placement: the Vanderbilt strategy. Ann Cardiothorac Surg. 2014; 3(6): 563-569, doi: 10.3978/j. issn.2225-319X.2014.10.02, indexed in Pubmed: 25512895.

89. Reichart D, Brand CF, Bernhardt AM, et al. Analysis of minimally invasive left thoracotomy HVAD implantation: a single-center experience. Thorac Cardiovasc Surg. 2019; 67(3): 170-175, doi: 10.1055/s-0038-1649493, indexed in Pubmed: 29804285.

90. McGee E, Danter M, Strueber M, et al. Evaluation of a lateral thoracotomy implant approach for a centrifugal-flow left ventricular assist device: The LATERAL clinical trial. J Heart Lung Transplant. 2019; 38(4): 344-351, doi: 10.1016/j.healun.2019.02.002, indexed in Pubmed: 30945636.

91. Wieselthaler GM, Klein L, Cheung AW, et al. Two-year follow up of the LATERAL clinical trial: a focus on adverse events. Circ Heart Fail. 2021; 14(4): e006912, doi: 10.1161/CIRCHEARTFAILURE.120.006912, indexed in Pubmed: 33866829.

92. Mohite PN, Sabashnikov A, Raj B, et al. Minimally invasive left ventricular assist device implantation: a comparative study. Artif Organs. 2018; 42(12): 1125-1131, doi: 10.1111/aor.13269, indexed in Pubmed: 30443997.

93. Maltais S, Anwer LA, Tchantchaleishvili V, et al. Left lateral thoracotomy for centrifugal continuous-flow left ventricular assist device placement: an analysis from the mechanical circulatory support research network. ASAIO J. 2018; 64(6): 715-720, doi: 10.1097/MAT.0000000000000714, indexed in Pubmed: 29095733.

94. Pasrija C, Sawan MA, Sorensen E, et al. Less invasive left ventricular assist device implantation may reduce right ventricular failure. Interact Cardiovasc Thorac Surg. 2019; 29(4): 592-598, doi: 10.1093/icvts/ivz143, indexed in Pubmed: 31326991.

95. Kormos RL, Cowger J, Pagani FD, et al. The society of thoracic surgeons intermacs database annual report: evolving indications, outcomes, and scientific partnerships. J Heart Lung Transplant. 2019; 38(2): 114-126, doi: 10.1016/j.healun.2018.11.013, indexed in Pubmed: 30691593.

96. Kocabeyoglu SS, Kervan U, Sert DE, et al. Is it Possible to Implant HeartMate 3 Less Invasively? New Pump, New Approach. Artif Organs. 2018; 42(12): 1132-1138, doi: 10.1111/aor.13289, indexed in Pubmed: 30393885.

97. Dowling RD, Gray LA, Etoch SW, et al. Initial experience with the AbioCor implantable replacement heart system. J Thorac Cardiovasc Surg. 2004; 127(1): 131-141, doi: 10.1016/j. jtcvs.2003.07.023, indexed in Pubmed: 14752423.

98. Pae WE, Connell JM, Adelowo A, et al. Does total implantability reduce infection with the use of a left ventricular assist device? The LionHeart experience in Europe. J Heart Lung Transplant. 2007; 26(3): 219-229, doi: 10.1016/j.healun.2006.12.007, indexed in Pubmed: 17346623.

99. Pya Y, Maly J, Bekbossynova M, et al. First human use of a wireless coplanar energy transfer coupled with a continuous-flow left ventricular assist device. J Heart Lung Transplant. 2019; 38(4): 339-343, doi: 10.1016/j.healun.2019.01.1316, indexed in Pubmed: 30945635.

100. Mehra MR, Gustafsson F. Left ventricular assist devices at the crossroad of innovation in advanced heart failure. J Card Fail. 2021; 27(11): 1291-1294, doi: 10.1016/j.cardfail.2021.06.003, indexed in Pubmed: 34139365. 